\title{
Article \\ Production of Synthetic Models for Neuro-Oncology Training by Additive Manufacturing
}

\author{
Vicentiu Saceleanu ${ }^{1}\left(\mathbb{D}\right.$, Rubén Paz $^{2} * \mathbb{D}^{\mathbb{D}}$, Joshua García ${ }^{2}$, Yamilet Rivero ${ }^{2}$, Cosmin-Nicodim Cîndea ${ }^{1}(\mathbb{D}$, \\ Ilaria Cacciotti ${ }^{3}$ and Mario Monzón ${ }^{2}$ (I) \\ 1 Department of Neurosurgery, Faculty of Medicine, Lucian Blaga University, 550024 Sibiu, Romania; \\ vicentiu.saceleanu@gmail.com (V.S.); cindea.cos@gmail.com (C.-N.C.) \\ 2 Mechanical Engineering Department, Edificio de Ingenierías, Campus de Tafira Baja, Universidad de Las \\ Palmas de Gran Canaria, 35017 Las Palmas, Spain; joshua.garcia@ulpgc.es (J.G.); \\ yamilet.rivero@ulpgc.es (Y.R.); mario.monzon@ulpgc.es (M.M.) \\ 3 Department of Engineering, University of Rome "Niccolò Cusano", INSTM RU, Via Don Carlo Gnocchi 3, \\ 00166 Rome, Italy; ilaria.cacciotti@unicusano.it \\ * Correspondence: ruben.paz@ulpgc.es
}

Citation: Saceleanu, V.; Paz, R.; García, J.; Rivero, Y.; Cîndea, C.-N.; Cacciotti, I.; Monzón, M. Production of Synthetic Models for Neuro-Oncology Training by Additive Manufacturing. Appl. Sci. 2021, 11, 11823. https://doi.org/ 10.3390/app112411823

Academic Editor: Manoj Gupta

Received: 16 November 2021 Accepted: 10 December 2021 Published: 13 December 2021

Publisher's Note: MDPI stays neutral with regard to jurisdictional claims in published maps and institutional affiliations.

Copyright: (c) 2021 by the authors. Licensee MDPI, Basel, Switzerland. This article is an open access article distributed under the terms and conditions of the Creative Commons Attribution (CC BY) license (https:/ / creativecommons.org/licenses/by/ $4.0 /)$.

\begin{abstract}
Neurosurgery is one of the medical specialties in which the practical training of students is more limiting since it requires a high degree of preparation for the interventions to be satisfactory. That is why the manufacture of synthetic models through additive manufacturing (AM) arises to develop the skills that the neurosurgeon requires. The present work is aimed at validating the use of AM for the neurosurgery training. To this regard, a meningioma case study was considered, and suitable materials and more appropriate AM technology were identified for a low-cost production of synthetic models of both skulls and brains with tumors. The skull was manufactured by material extrusion AM with two materials, a commercial composite filament composed of polylactic acid (PLA) with calcium carbonate (used in the area to be treated during the cutting process, due to its mechanical properties more comparable to those of the native bone, with $30 \%$ infill density) and standard PLA without additives (used in the rest of the model, with $20 \%$ infill density). On the other hand, different casting silicones in different proportions were tested under compression molding to find the best combination to mimic the brain and tumor. Ten synthetic models of a real-case meningioma were manufactured and used as training material by students in the neurosurgery sector, who rated the proposed training approach very highly, considering the employment of printed models as a key resource for improving their surgical skills.
\end{abstract}

Keywords: additive manufacturing; synthetic models; skull; brains with tumors; neurosurgery; segmentation

\section{Introduction}

Additive manufacturing (AM), commonly known as 3D printing, is one of the greatest manufacturing revolutions. It consists in the creation of physical objects by successively joining material, layer upon layer, according to the corresponding 3D model data. AM technologies have opened new paths for the manufacture of products, with application in several fields [1]. In the medical sector, AM has had a great relevance due to the customization and freeform capabilities, which allows for the production of personalized implants and tools, as well as the production of real-case anatomic models [2]. In the field of neurosurgery, AM has had a great impact as it enables the production of anatomically specific models of patients with diseases, allowing for the acquisition of surgical skills with the testing of these simulated models before facing real surgery, planning a future intervention by having the possibility of previewing the physical organ in all its perspectives. This makes these 3D models an excellent tool for teaching and surgical training without risk of harm to the patient [3]. 
In producing a 3D printed anatomical model, the first step consists in obtaining the images provided by a scanning technique such as computed tomography (CT). These images, usually in a DICOM (Digital Imaging and Communication on Medicine) format, are then processed in a specific software (e.g., 3DSlicer) to obtain the segmented model of the tissue of interest. This model is transformed into a STL file that can be imported in a design program or, in some cases, directly 3D printed. This approach for obtaining anatomical models for teaching and surgical training has been used by several authors. Shah et al. reviewed numerous works about the employment of 3D printing to create threedimensional models for surgical training in the case of different pathologies [4]. Among them, Mashiko et al. (2015) produced the 3D printing of models for clipping of cerebral aneurysms [5]. They manufactured an aneurysm model that simulated the geometry and texture of the real organ. Other examples of brain aneurysm fabrication were provided by Wurm et al. [6] and Kimura et al. [7].

On the other hand, Shah et al. also described the contribution of several authors regarding models of skulls and tumors. Waran et al. [8] used AM to create an anatomical model with brain pathologies to enhance the neurosurgeons educational experience, which included simulated models in texture and geometry of the skull, brain, tumor, and dura mater. Ryan et al. [9] and Nagassa et al. [10] manufactured all the previous models and included a brain aneurysm in order to perform the surgical clipping intervention with these simulated models. Wanibuchi et al. [11] and Kondo et al. [12] conducted research on the 3D printing of skulls and tumors using different techniques, allowing, among others, to print models with multiple materials and colors. Finally, Dho et al. also produced models of specific brain tumors to use in daily clinical practice for neurosurgery [13].

Training in neurosurgery is a long-term process, which lasts in European countries for at least 6-7 years, necessary for learning the basic maneuvers, followed by continuous training throughout one's career. This long training process involves high costs for the health system and a higher risk in the medical act, taking into account that every new technical procedure that a surgeon performs will be done on a real patient.

For these reasons, the employment of synthetic models by AM is considered a promising approach for the neurosurgeons training, but, according to the literature [14,15], most of the training models developed thus far for neurosurgery do not combine the realism of the model with economic manufacturing procedures. This is of special relevance for training applications where several replicas of the same real case are needed.

In order to overcome this criticism, the present work aimed at validating the use of an economical manufacturing approach based on material extrusion AM (low-cost technology), combined with silicone casting for the production of the brain model (leading to a more economic and faster production method, especially advantageous when several replicas are needed, e.g., training workshops for students). A real brain meningioma tumor case was considered, and all the main tissues involved during the real intervention were produced (skull, dura mater, brain, and tumor). Appropriate materials were selected; in particular, materials that resemble the real tissues were used just in the working areas (to be submitted to the surgery), while more economic and easier-to-process materials were used for the rest of the models (non-working areas). The developed synthetic models of the meningioma case were successfully used in a training workshop for medicine students, and their satisfactory level was evaluated, as well as their suggestions for the optimization of the proposed training strategy.

\section{Materials and Methods}

This section describes the materials used to mimic the skull, brain, tumor, and dura mater, as well as the methodology followed for the simulation of the meningioma case study. 


\subsection{Materials}

\subsubsection{Skull}

For the reproduction of the skull model, material extrusion AM was considered, as it is a low-cost technology. Regarding the material, a previous work was carried out [16] in which the properties of two filaments, Smartfi ${ }^{\circledR}$ PLA without additives and Smartfil ${ }^{\circledR}$ EP (a filament made of $70 \%$ PLA and $30 \% \mathrm{CaCO}_{3}$ ), were compared with the properties of a cow bone. The three materials were subjected to several tests. First of all, a three-point flexural test (following the ISO 178 standard) was carried out to determine the flexural elastic modulus and flexural strength. Five samples of each material were produced $(80 \times 10 \times 4 \mathrm{~mm})$ and subjected to the flexural test with a distance between supports of $64 \mathrm{~mm}$ and crosshead speed of $10 \mathrm{~mm} / \mathrm{min}$. On the other hand, samples of the three materials were drilled and milled using the same cutting parameters while a PCE-FG1K load cell (1 kN maximum force, from PCE Instruments) was fixed to the clamping system and registered the cutting forces in order to find the maximum vertical force during drilling and the maximum horizontal force in the feeding direction during milling. A geometrical evaluation (dimensions) of the chips generated during milling was also carried out, as well as a Shore D hardness test. Finally, the materials were also tested by a neurosurgeon (drilling and cutting with specialized tools for neurosurgery). Table 1 summarizes the results of this previous work [16]. For each property analyzed (rows), a tick was added to the material (columns) that achieved the most similar behavior to the real bone (and a cross for the other material). According to the results, PLA with additives was more similar to real bone in terms of flexural elastic modulus and maximum milling force. However, for the rest of parameters, Smartfil ${ }^{\circledR}$ EP was more similar to real bone than standard Smartfil ${ }^{\circledR}$ PLA.

Table 1. Criteria for the choice of material for the skull model [16].

\begin{tabular}{ccc}
\hline Property & Smartfil $^{\circledR}$ EP & PLA Without Additives \\
\hline Flexural elastic modulus & $\times$ & $\checkmark$ \\
Flexural strength & $\checkmark$ & $\times$ \\
Maximum cutting force (drilling) & $\checkmark$ & $\times$ \\
Maximum cutting force (milling) & $\times$ & $\checkmark$ \\
Chip behavior & $\checkmark$ & $\times$ \\
Surface hardness (Shore D) & $\checkmark$ & $\times$ \\
Validation by a neurosurgeon & $\checkmark$ & $\times$ \\
\hline
\end{tabular}

However, it has been proven that making the entire skull model with Smartfii ${ }^{\circledR}$ EP (Smart Materials 3D printing SL, Spain) can lead to printing problems due to the presence of the ceramic additive, which hinders the extrusion. For this reason, this material was applied only to the work area (area surrounding the tumor), while the rest of the skull (not relevant for the intervention) was made with standard Smartfil ${ }^{\circledR}$ PLA filament (Smart Materials 3D printing SL, Spain) (20\% rectilinear filling, with 45 and $-45^{\circ}$ orientation between layers), as it is more stable and faster to print, thus improving the manufacturing process. With this solution, work performance was improved, speeding up the process and avoiding printing errors.

In addition, we decided to carry out a trial with different filling densities of the Smartfil ${ }^{\circledR}$ EP to choose which is the most suitable for manual cutting with a Gigli saw.

Therefore, after conducting the test with different fill densities, we concluded that the one with the greatest ease of manual cutting was 30\% rectilinear filling density (45 and $-45^{\circ}$ orientation between layers).

\subsubsection{Brain}

To simulate the brain, we identified the optimal material in a preliminary phase, comparing the elasticity modulus of three different samples, and taking into account the fact that the reference elastic modulus of the brain is $21.16 \mathrm{kPa}$ [17-21].

The three different materials analyzed in the preliminary tests were: 
- $\quad$ AljaSafe ${ }^{\circledR}$ : alginate used to produce molds. This material was processed in different proportions, but it was discarded due to its dimensional instability and higher stiffness compared to a real brain. These samples lose their elastic properties over time, thus resulting in a hard and stiff material that is not feasible for this application.

- Contor 5005: three-component silicone with tin catalyst (A:B:C). Six samples of five different proportions were manufacture with the Contor 5005. The A:B ratio was maintained according to the recommendation of the manufacturer (100:2.5), while the $\mathrm{C}$ content compared to $\mathrm{A}+\mathrm{B}$ was modified in different percentages because it is important to check the behavior of the material when increasing or decreasing the catalyst. The codes used for these five groups were C30, C50, C70, C90, and C100.

- Ecoflex ${ }^{\circledR}$ 00-10 (Smooth-On, Inc., Macungie, PA, USA): two-component silicone with platinum catalyst $(\mathrm{A}, \mathrm{B})$. Six samples of three different proportions were manufactured with this material. The A:B proportions were 1.0:0.5 (E0.5), 1:1 (E1), and 1.0:1.5 (E1.5).

These samples were subjected to mechanical characterization under compression load. The mechanical testing was carried out using a LIYI (LI-1065, Dongguan Liyi Environmental Technology Co., Ltd., Dongguan, China) testing machine in displacement control mode. The crosshead speed was set to $10 \mathrm{~mm} / \mathrm{min}$, and the compression modulus was calculated as the slope of the initial segment in the stress-strain graph.

The results of the compression tests, in terms of average compressive elastic modulus, are compared in Figure 1.

\section{Average compressive elastic modulus ( $\mathrm{kPa})$}

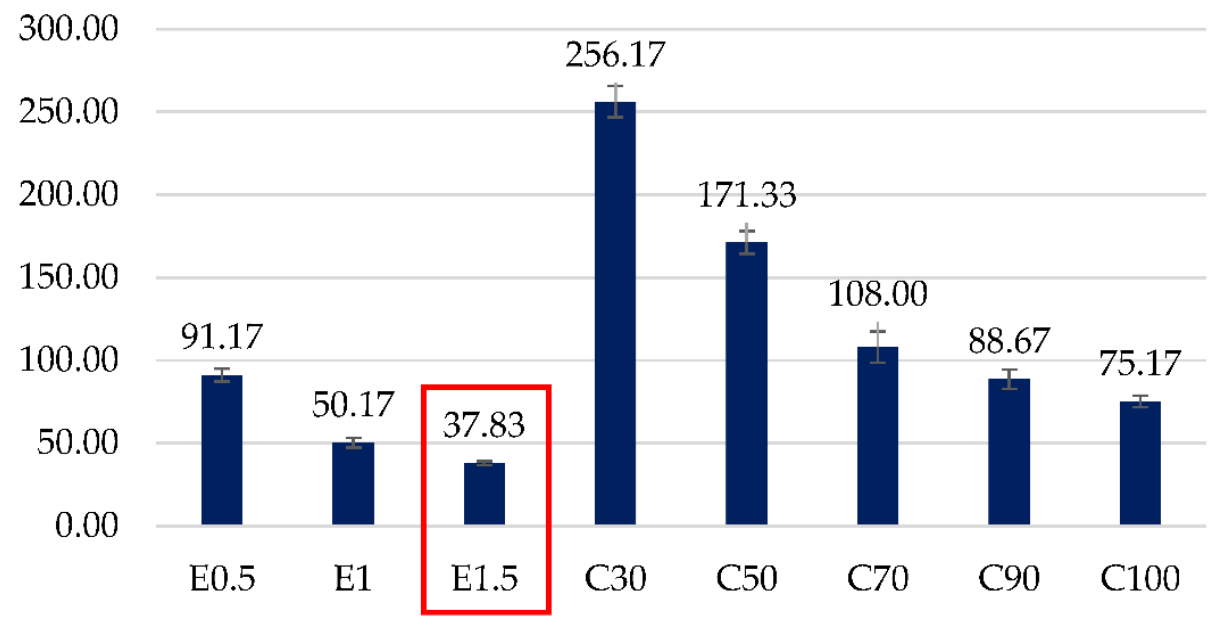

Figure 1. Compressive elastic modulus of the different groups tested with the preliminary selection to simulate the brain.

According to the acquired data, E1.5 sample achieved the most similar compressive elastic modulus $(37.83 \mathrm{kPa})$ to the reference value $(21.16 \mathrm{kPa})$, even if still far from it. To reduce the stiffness, we incorporated a new component (Slacker, Smooth-On, Inc., Macungie, PA, USA). Four different groups with different proportions of silicone component and Slacker were produced (A:B:Slacker) and subjected to compression tests to obtain the modulus of elasticity. Table 2 summarizes these results and the standard deviation of all of them.

Table 2. Mean modulus of elasticity and standard deviation of the tested samples (Ecoflex A:B:Slacker).

\begin{tabular}{|c|c|c|}
\hline $\begin{array}{l}\text { Mix Groups } \\
\text { (Ecoflex Comp. A: Ecoflex Comp. B: Slacker) }\end{array}$ & $\begin{array}{l}\text { Mean Modulus of } \\
\text { Elasticity (kPa) }\end{array}$ & $\begin{array}{l}\text { Standard Deviation } \\
\text { SD (kPa) }\end{array}$ \\
\hline Group A (1:1:1) & 40.41 & 3.45 \\
\hline Group B (1:1:2) & 37.90 & 1.01 \\
\hline Group C (1:1:3) & 31.29 & 6.10 \\
\hline Group D (1:1:4) & 27.95 & 2.62 \\
\hline
\end{tabular}


Finally, among the produced samples and in accordance with the neurosurgeons' feelings, the best material to mimic the brain was group C (1:1:3), with an elastic modulus of $31.29 \mathrm{kPa}$.

On the other hand, a mold was needed for the silicone casting. This mold was produced by material extrusion AM with Smartfil ${ }^{\circledR}$ PLA (20\% filling).

\subsubsection{Tumor: Meningioma}

The meningioma [22] is a mass with a firm texture and higher consistency than the brain. To mimic this tissue, we tested the previous silicone samples by neurosurgeons, and the mixture Ecoflex 00-10 1:1 (A:B) was selected.

Furthermore, this type of tumor usually has calcium deposits or calcification [23], which are small white spots that are more rigid than the tumor. Therefore, to reproduce these calcium deposits, we crushed the excess Smartfil ${ }^{\circledR}$ PLA from other models (support material) into small pieces and added it to the mixture.

On the other hand, red pigment was added to improve the realism of the tumor.

As in the case of the brain, the tumor was manufactured by casting the mixture in a mold, which was also manufactured by material extrusion AM. Table 3 summarizes the used materials and the corresponding amount that simulate the tumor and the tumor mold.

Table 3. Material for the tumors.

\begin{tabular}{ccc}
\hline Models & Material & Ratio or Amount \\
\hline Meningioma & Mix Ecoflex 00-10 comp. A:B & $1: 1$ \\
\hline With color & Red pigment & $3 \%$ \\
\hline And calcium deposits & Smartfil ${ }^{\circledR}$ PLA & Crushed \\
\hline Meningioma mold & Smartfil $^{\circledR}$ PLA & $20 \%$ filling \\
\hline
\end{tabular}

\subsubsection{Dura Mater}

The dura mater is the layer in the outermost part of the brain, attached to the skull, being the hardest and most condensed of all [24]. To simulate it, we rolled a mixture of the Ecoflex 00-10 1:1 (A:B) on a flat surface and left it as a thin layer.

\subsection{Model Segmentation}

Segmentation is the process of isolating an area of interest in the data files, where the dataset is a series of DICOM images, in this case from a CT scan. These images were imported into a free access software 3D Slicer, which segments the images to produce a STL file that is then imported into the software Meshmixer to convert it to solid STL. The better the image quality, the easier the segmentation process.

\subsubsection{Skull}

To obtain the final model of the skull, we performed the segmentation (Figure 2a) and cutting (Figure $2 b$ ) with the different 3DSlicer tools. For the segmentation step, the 'threshold' tool (in the segment editor) was used, adjusting the range values until the selected pixels matched the zone of the bone. After this, the cutting of the lower part of the bone was carried out by using the 'scissors' tool. Finally, the resulting model was saved as an STL file and converted into a solid STL file in the Meshmixer software ('make solid' tool, in the 'edit' menu). 

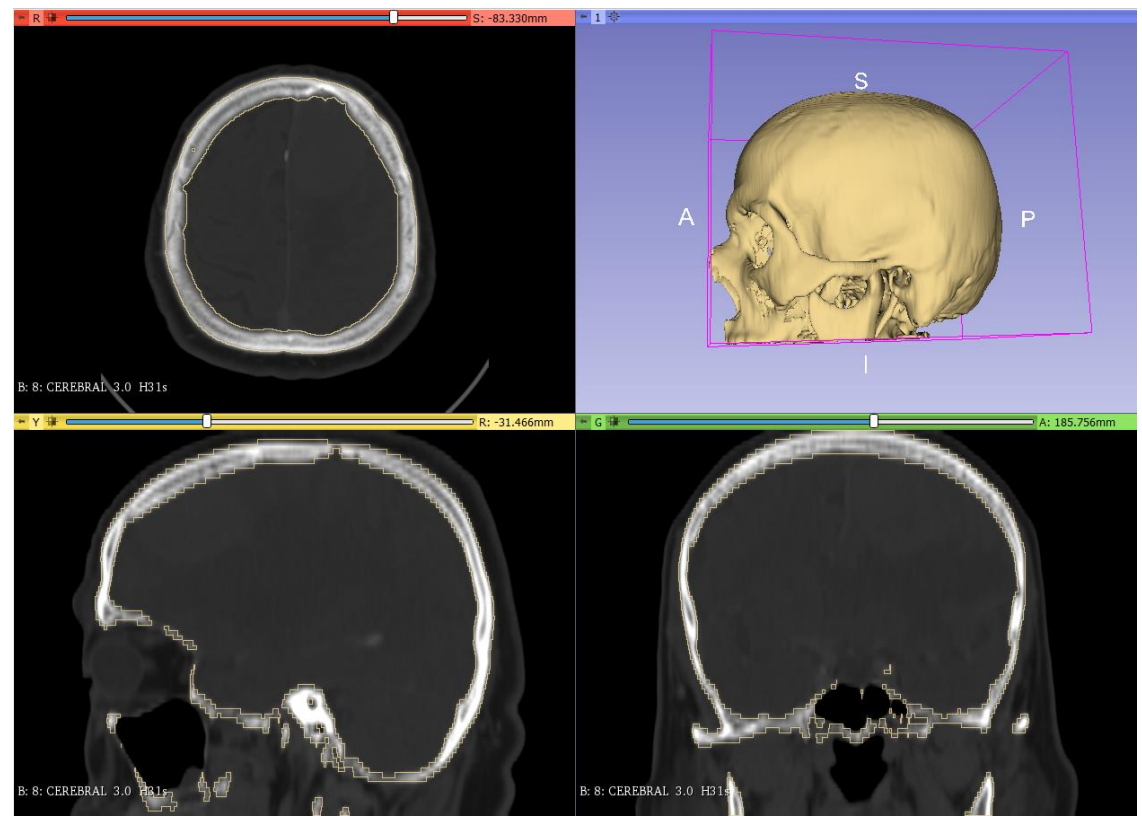

(a)
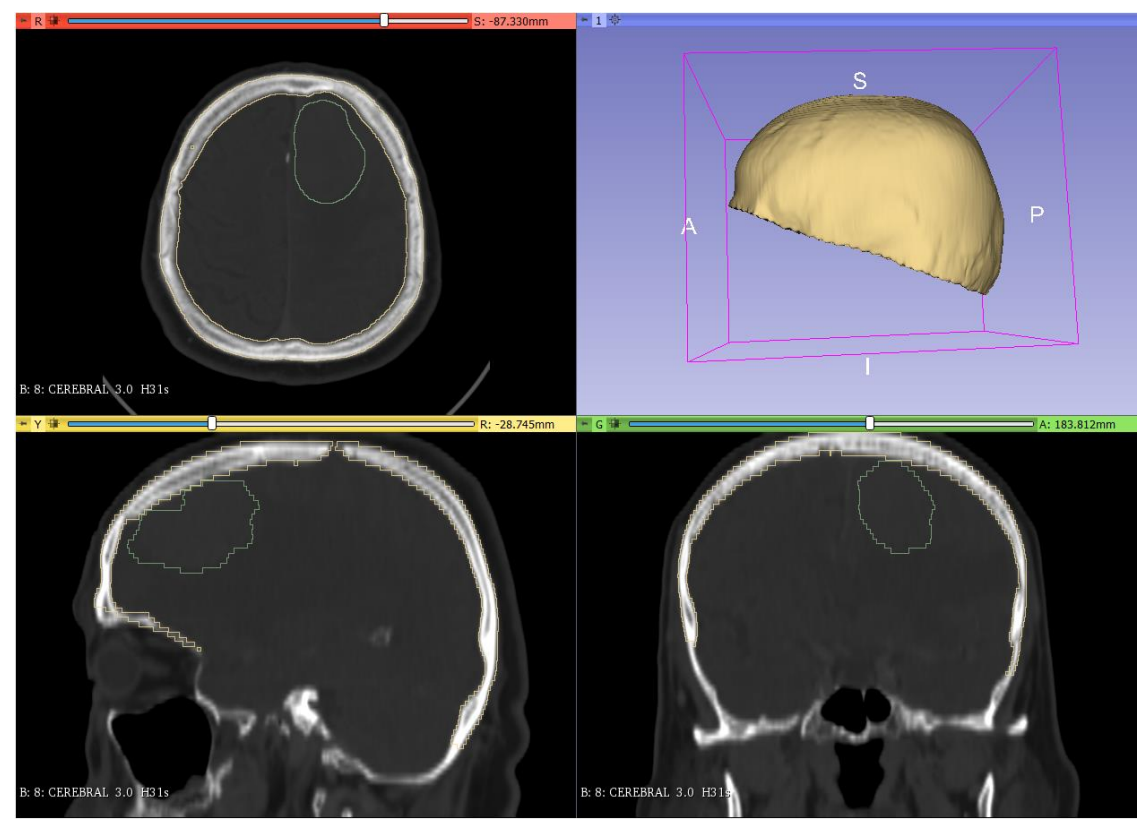

(b)

Figure 2. Segmentation (a) and cutting (b) of the skull model from the DICOM images in 3DSlicer.

\subsubsection{Tumor Mold}

As mentioned above, the production of a tumor prototype requires a mold where the silicone mixture has to be poured to obtain the desired geometric model. To do this, the model was segmented (Figure 3a) using a similar approach to that applied for the bone segmentation. However, since the tumor is not easily differentiated from the brain, more manual work was needed. The first step was to apply the 'threshold' tool in the segment editor to try to select all the pixels corresponding to the tumor by adjusting the range of application. As the previous step was not accurate due to the color similarity between the brain and tumor, the 'erase' and 'paint' tools were used, layer by layer, to adjust the segmented area ('erase' to remove areas and 'paint' to add new areas to the segment). After this, a copy of the segmented model was made ('logical operators', 'copy' operation) with an added thickness of $10 \mathrm{~mm}$ ('margin' tool). Then, the original model was subtracted 
to the increased model ('logical operators' tool, 'subtract' operation), leaving a hollow segmented model as a mold (Figure 3b).

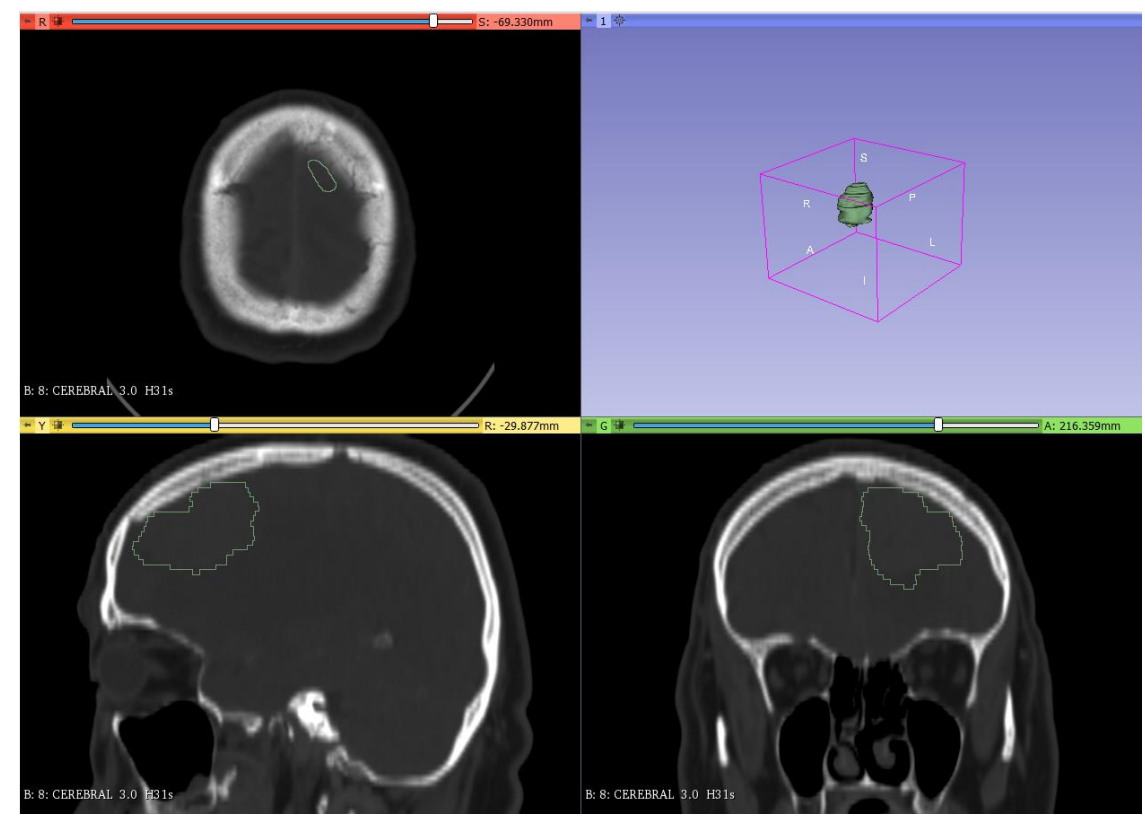

(a)
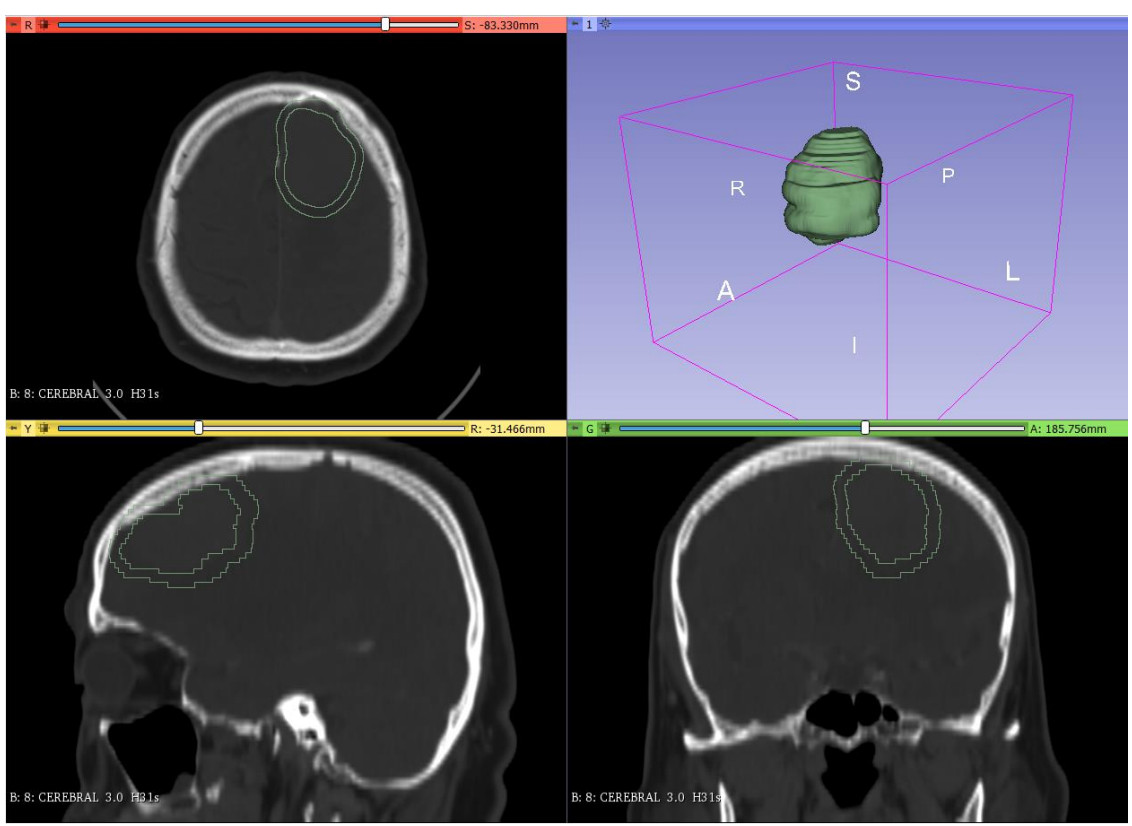

(b)

Figure 3. Segmentation (a) and creation of the tumor mold (b) from the DICOM images in 3DSlicer.

\subsubsection{Brain Mold}

In the making of the mold of the brain, the first step was to join the segmented model of the skull and the tumor (in the segment editor, 'logical operators' tool, 'add' operation) so that this mold had the shape of the tumor inside (Figure 4a). Then, the thickness was increased by $3 \mathrm{~mm}$ ('margin' tool) so that the molded brain had $3 \mathrm{~mm}$ of clearance with the skull. Finally, the model was cut ('scissors' tool) following the same plane as in the skull cutting (Figure 4b). 

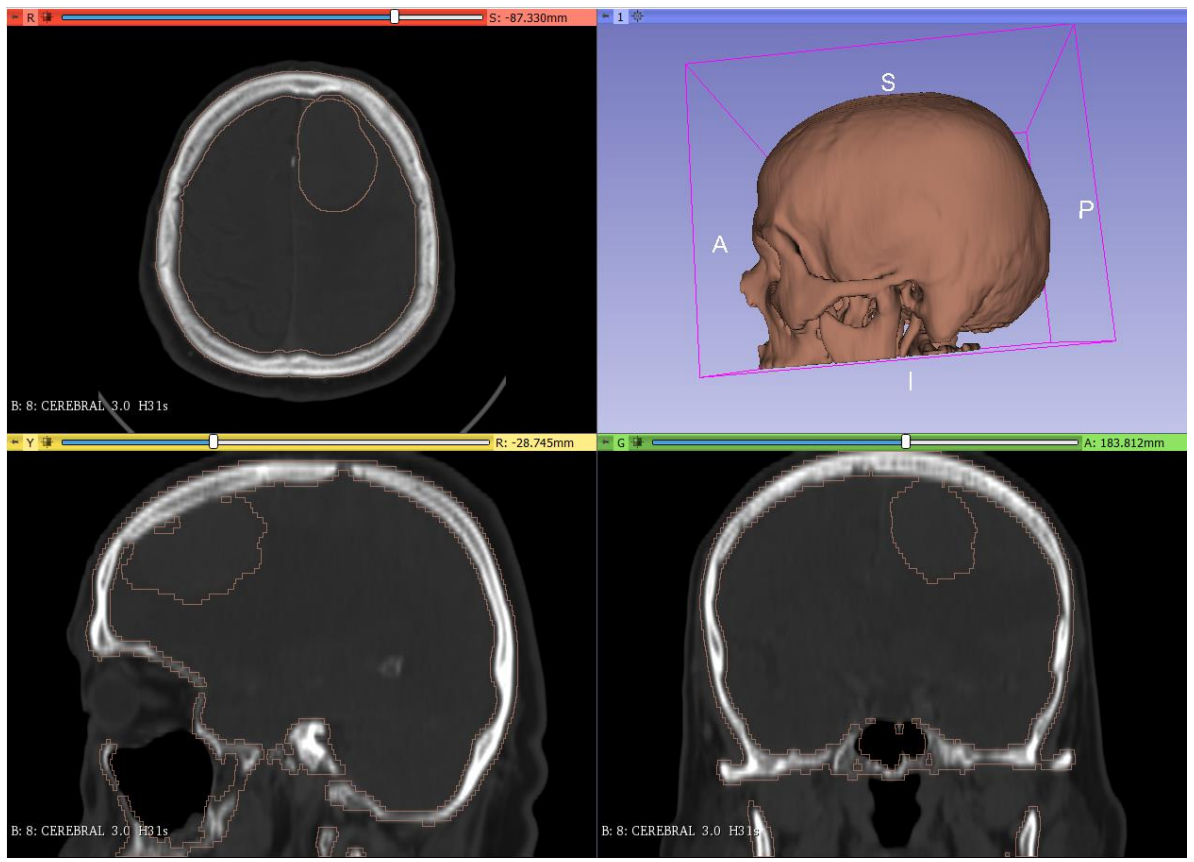

(a)
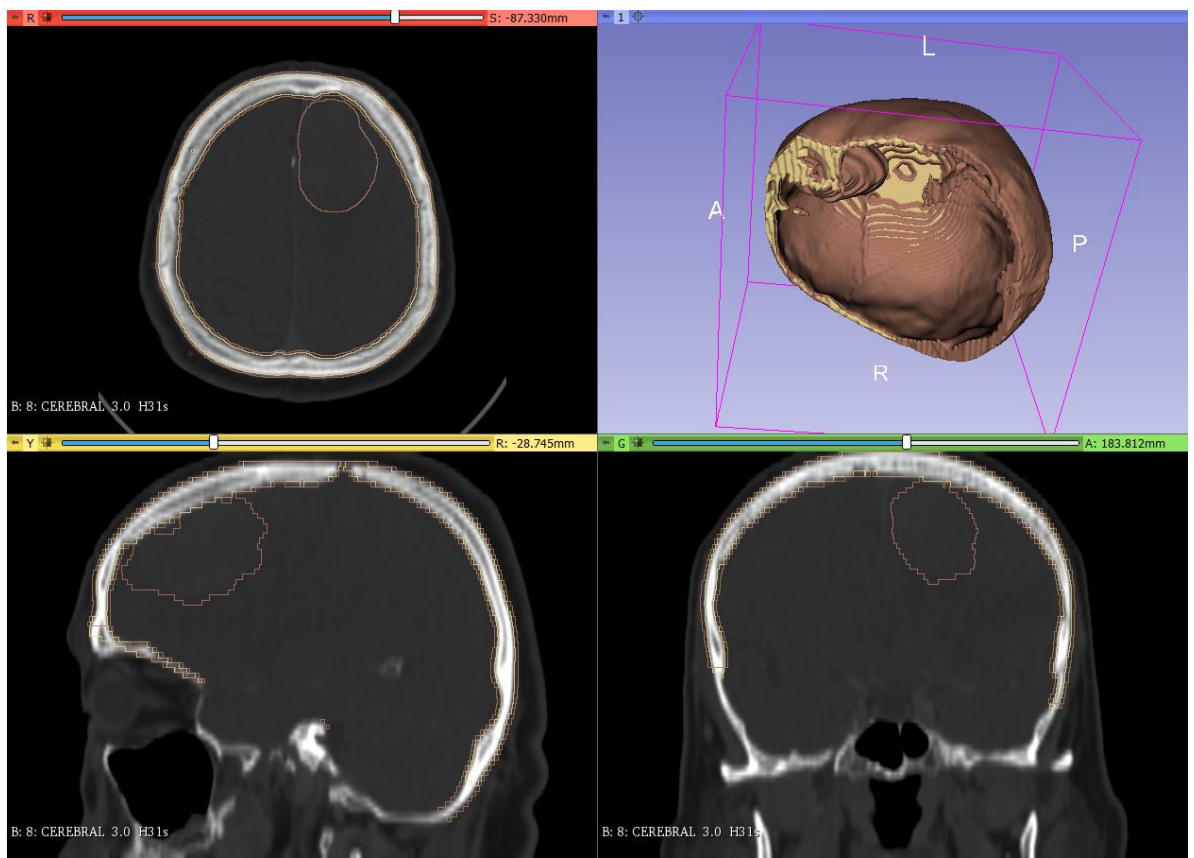

(b)

Figure 4. Segmentation (a) and creation of the brain mold (b) from the DICOM images in 3DSlicer.

Once all the models were segmented in 3DSlicer, they were imported into Meshmixer software to be converted into a solid STL file ('make solid' feature, in the edit menu).

\subsection{Model Design}

Once the solid STL files of the segmented models were obtained, they were imported into SolidWorks software to make the design according to the conditions of each model. 


\subsubsection{Skull}

Regarding the skull model, the lower part was cut to obtain a perfectly flat surface on the bottom. Then, as mentioned above, the work area was defined to divide the skull into two parts. To do this, a sketch was defined in the area of the tumor and the skull was split so that the work area could be 3D printed with Smartfil ${ }^{\circledR} \mathrm{EP}$ material and the rest with Smartfil ${ }^{\circledR}$ PLA.

\subsubsection{Brain Mold}

Regarding the brain mold model, the first step was to cut the lower part to obtain a perfectly flat surface, and then, to facilitate the demolding process in the tumor area, we divided the mold into two parts. Finally, a base was added at the bottom to provide more stability to the mold for the silicone pouring.

\subsubsection{Mold for the Working Area Inside the Brain Mold}

On the other hand, since the Slacker component of the Ecoflex silicone was significantly more expensive than the $\mathrm{A}$ and $\mathrm{B}$ components, the brain model was made with two different silicone mixtures: the selected one (1:1:3, A:B:Slacker) for the working area located in the surroundings of the tumor (softer silicone), and the silicone without Slacker (1:1, A:B) for the rest of the brain, as these regions will not be used during the intervention. This allows for reduction of the material cost without adversely affecting the quality of the synthetic model. To materialize this idea, we designed a mold that defines the work area to separate both mixtures. Additionally, a ring that fits with the upper part of the brain mold was added to this mold, thus allowing the correct position during the silicone pouring.

\subsubsection{Tumor Mold}

Regarding the brain mold model, it was also divided into two parts for the demolding process. Then, a feeding hopper was designed in the upper part to facilitate the silicone pouring. Finally, a base was also designed to provide stability to the mold.

Figure 5 shows the final design of the models.

\subsection{Model Manufacturing}

The final models were manufactured by material extrusion AM. An Atom (ALT Design, Taiwan) and Ender3 (Creality 3D, Shenzhen, China) 3D printers were used with the corresponding selected materials and infill densities. Regarding the printing parameters, a $0.4 \mathrm{~mm}$ nozzle was used for the extruders, with a manual width of $0.6 \mathrm{~mm}$ (also for the first layer), a layer height of $0.3 \mathrm{~mm}, 3$ wall perimeters, and 3 top and bottom solid layers. The nozzle temperature was $200{ }^{\circ} \mathrm{C}$ for Smartfil ${ }^{\circledR}$ PLA and $210^{\circ} \mathrm{C}$ for Smartfil ${ }^{\circledR}$ EP. The default printing speed was $60 \mathrm{~mm} / \mathrm{s}$ for Smartfil ${ }^{\circledR}$ PLA and $40 \mathrm{~mm} / \mathrm{s}$ for Smartfil ${ }^{\circledR} \mathrm{EP}$, with a movement speed in the $x / y$-axis of $100 \mathrm{~mm} / \mathrm{s}$ and $40 \mathrm{~mm} / \mathrm{s}$ in the $z$-axis (for both materials). The layer fan was set at $100 \%$ from layer 2 , and the supports were defined with $30 \%$ infill density with no dense support layers. The bed temperature was $60{ }^{\circ} \mathrm{C}$ for both materials. No retractions were applied for the Smartfil ${ }^{\circledR}$ EP filament, while in the case of Smartfil ${ }^{\circledR}$ PLA, the retraction distance was $8 \mathrm{~mm}$ at $40 \mathrm{~mm} / \mathrm{s}$. Additionally, in the case of Smartfil ${ }^{\circledR} \mathrm{EP}$, a cleaning process was applied after every print, especially in the extruder gears. This filament is more fragile due to the ceramic content, leading to powder accumulation in the gear teeth. If this powder is not removed from time to time, filament jams may occur. 
a)
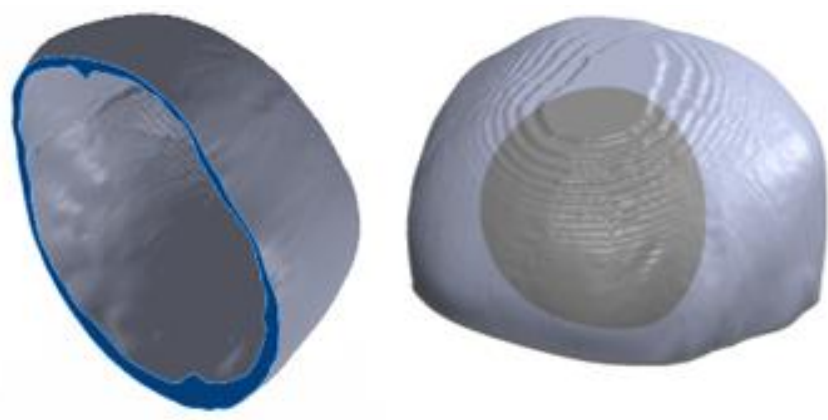

b)
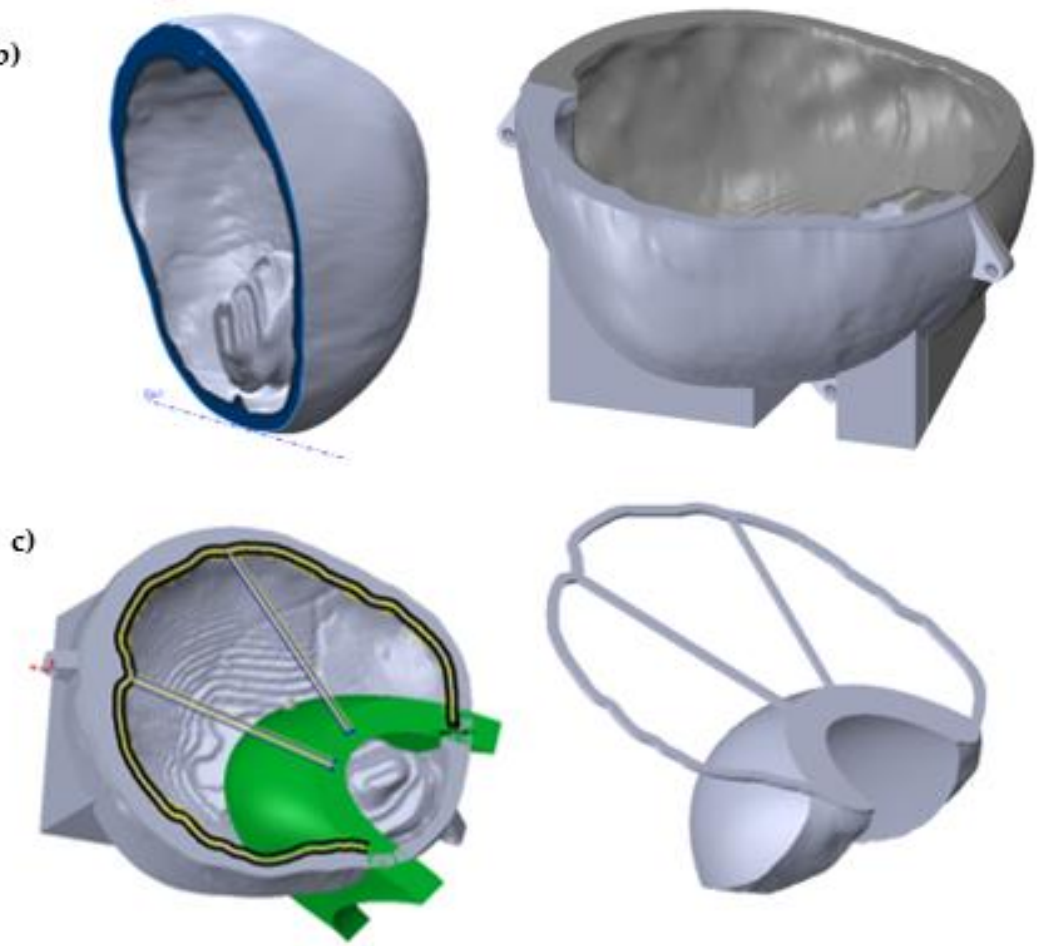

d)
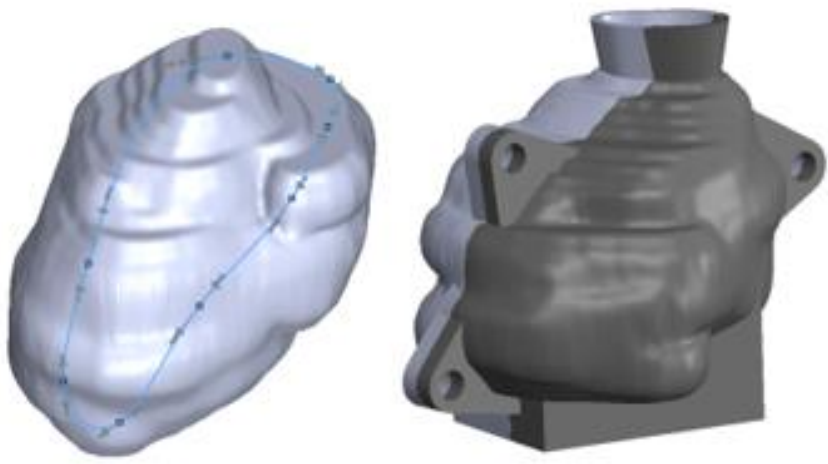

Figure 5. Features performed in SolidWorks to obtain the skull (a), the brain mold (b), the mold to define the working area inside the brain mold (c), and the tumor mold (d).

Figure 6 shows the 3D printed models. 


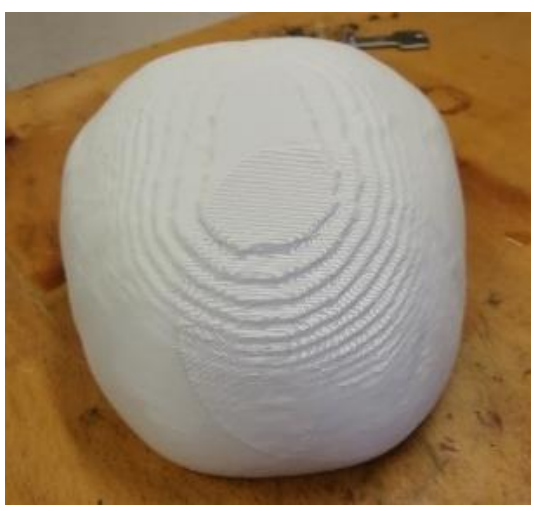

(a)

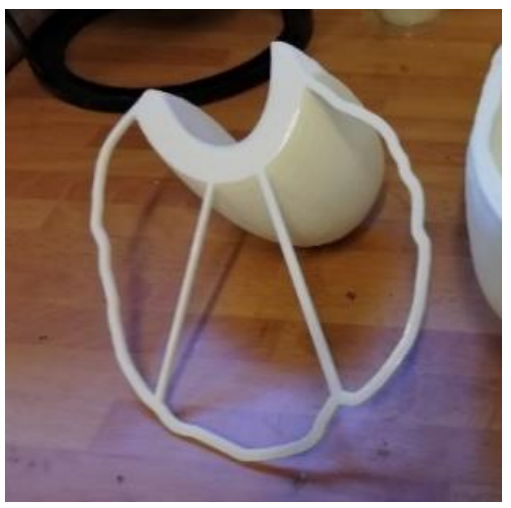

(c)

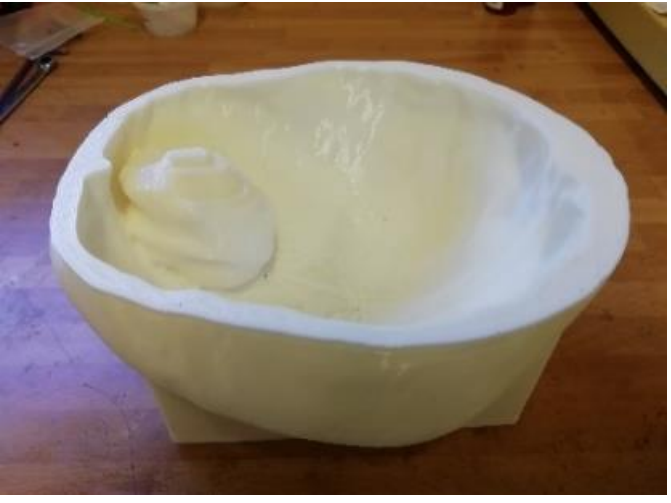

(b)

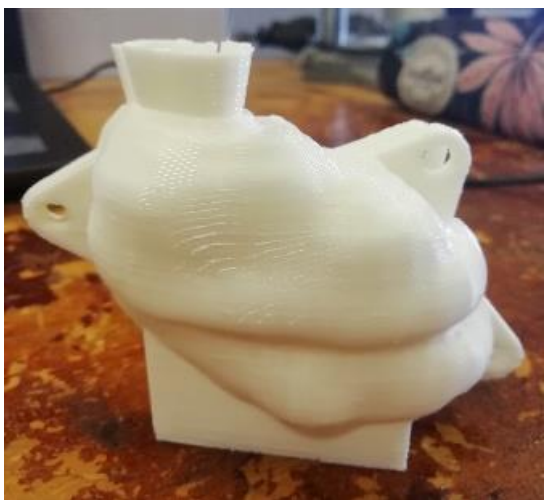

(d)

Figure 6. 3D printed skull (the visible layers were due to the slicing height of the CT scan, which was $2 \mathrm{~mm}$ in the vertical or $z$-axis) (a), the brain mold (b), the mold to define the working area inside the brain mold (c), and the tumor mold (d). Approximate dimensions: (a) skull with $180 \mathrm{~mm}$ length and $150 \mathrm{~mm}$ width from the top view, (b) brain mold with $205 \mathrm{~mm}$ length and $159 \mathrm{~mm}$ width from the top view, (c) mold inside brain mold with $155 \mathrm{~mm}$ length from the top view, and (d) tumor mold with $90 \mathrm{~mm}$ length and $70 \mathrm{~mm}$ width from the top view.

Once the different molds were produced, the silicon pouring was carried out. In the case of the brain that was manufactured with two different mixtures, the mold to define the working area (area surrounding the tumor) was placed inside the brain mold and a first pouring was made inside this mold with the chosen mixture, i.e., 1:1:3 (A:B:Slacker). Then, when the silicone had cured, the rest of the mix without Slacker was poured into the brain mold. In the case of the tumor, the chosen mixture 1:1 (A:B) with the red pigments and the crushed Smartfil ${ }^{\circledR}$ PLA was poured into the tumor mold. Finally, in the case of the dura mater, the chosen mixture 1:1 (A:B) was expanded on a surface to left a thin sheet. The results obtained by pouring the different silicone mixtures are shown in Figure 7.

Once all the models were manufactured using AM and the silicone casting pours, the final assembly was carried out, as shown in Figure 8. Ten replicas of the model were produced and screwed on to the corresponding fixation mechanism, which allowed the desired orientation for the intervention. Finally, these models were used as training materials in a neuro-oncology workshop for medicine students during the second BRAIN IT summer school. 


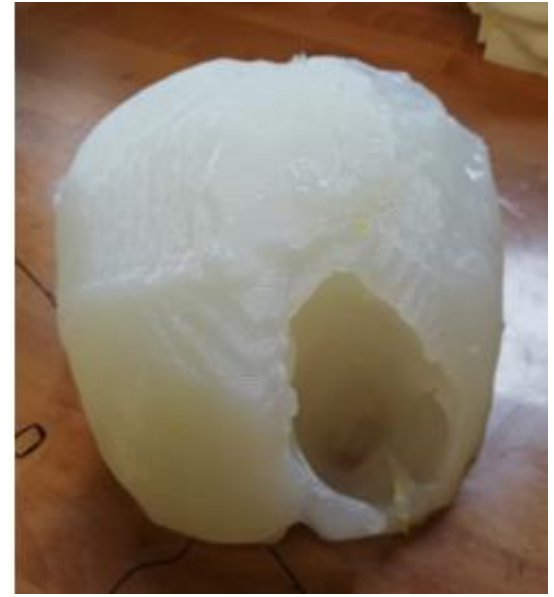

(a)

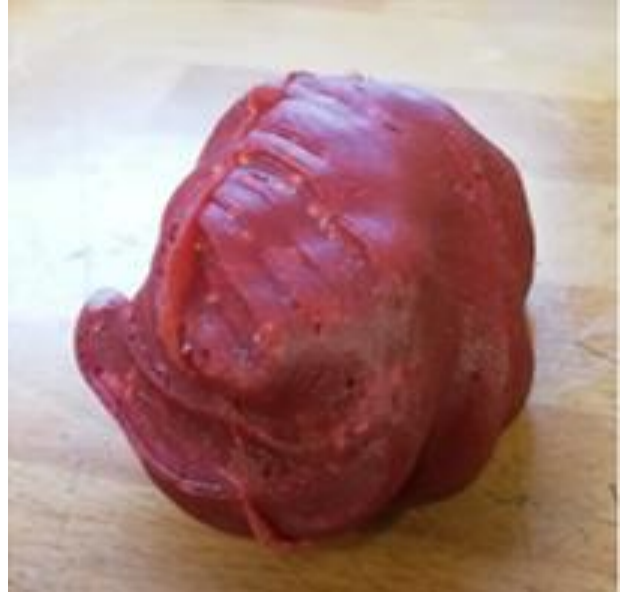

(b)

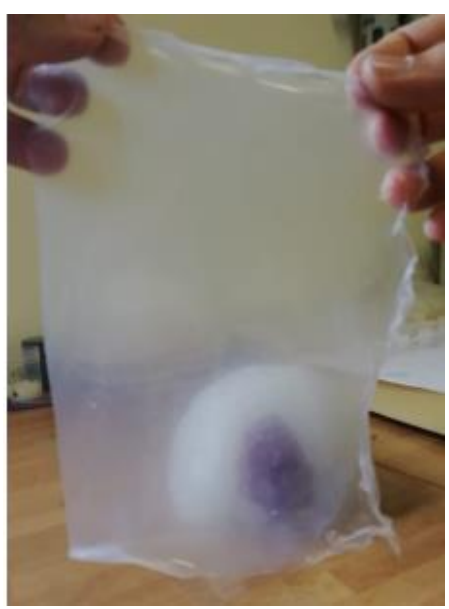

(c)

Figure 7. Casting of the different silicones in different proportions for the brain (a), tumor (b), and dura mater (c) models.

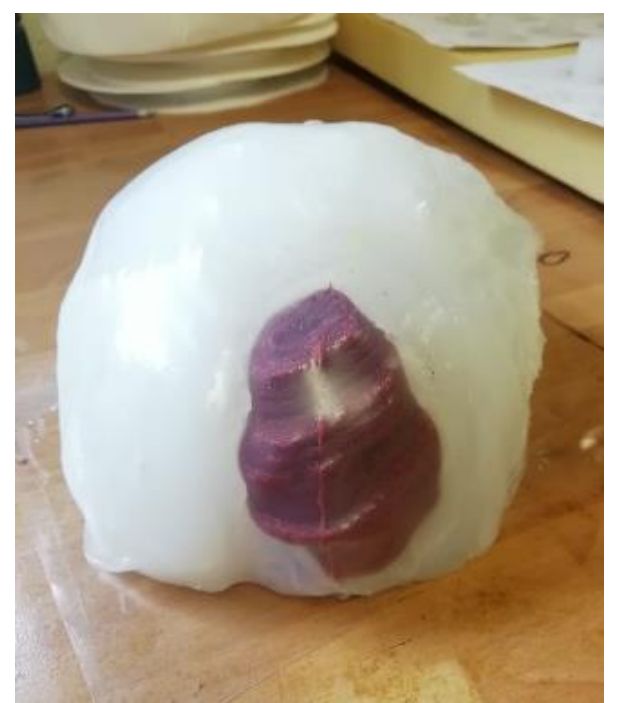

(a)

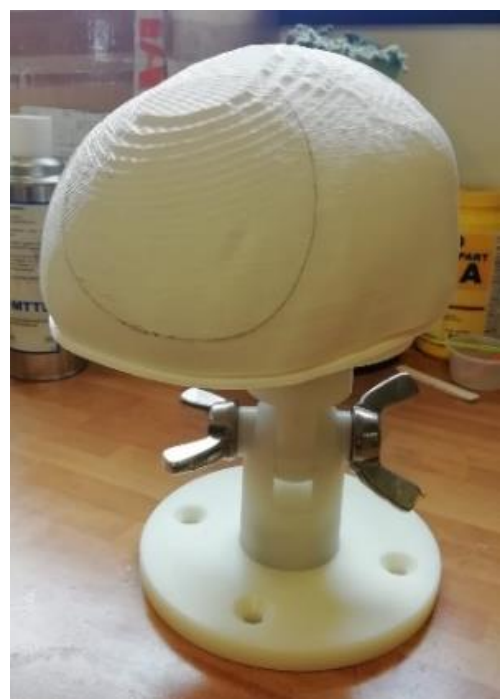

(b)

Figure 8. Final assembly: (a) brain with tumor and (b) complete model. 


\section{Results and Discussion}

The 10 produced models were used in a neuro-oncology practical workshop with 49 medicine students. This workshop was part of the Second Summer School of the BrainIT project (Brain Revealed: Innovative Technologies in Neurosurgery Study).

The following images (Figures 9-11) show the main moments of the workshop where the students in neurosurgery simulated the intervention using the synthetic models.

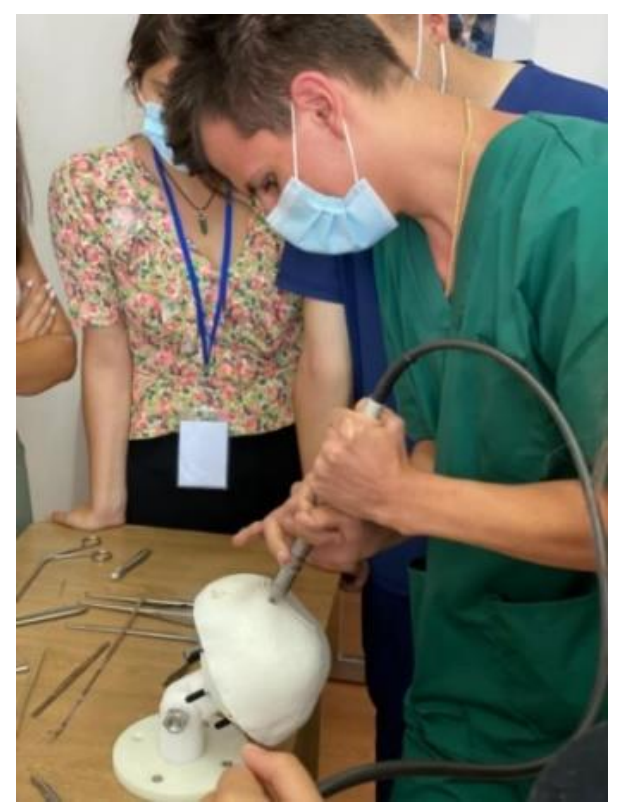

(a)

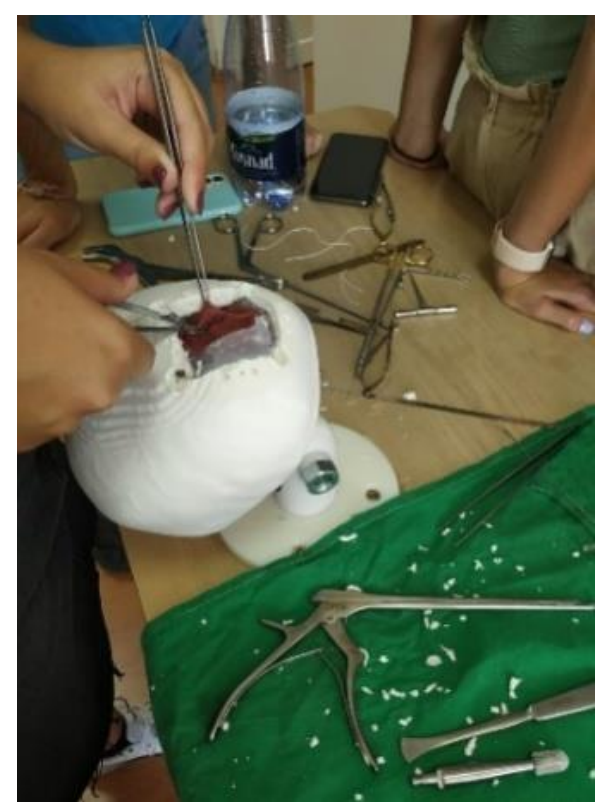

(b)

Figure 9. Students cutting the skull in the workshop (a) and removing the tumor (b).

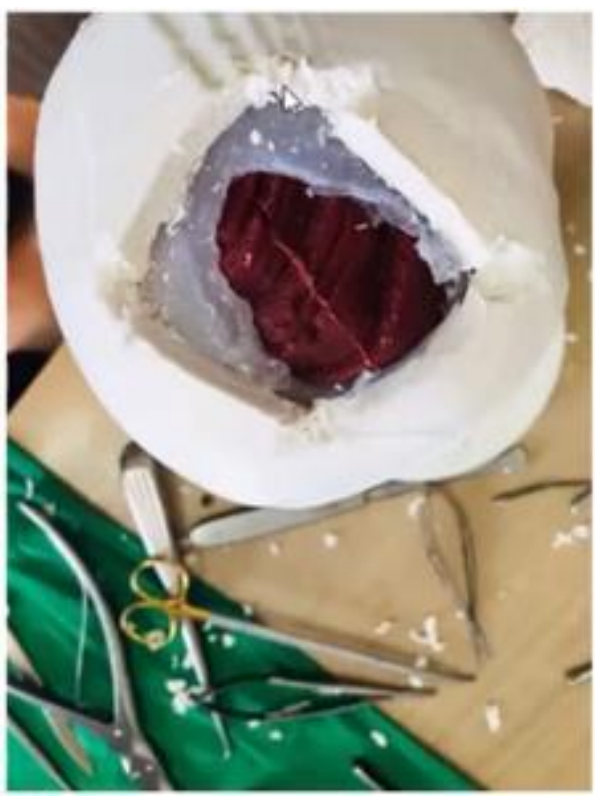

(a)

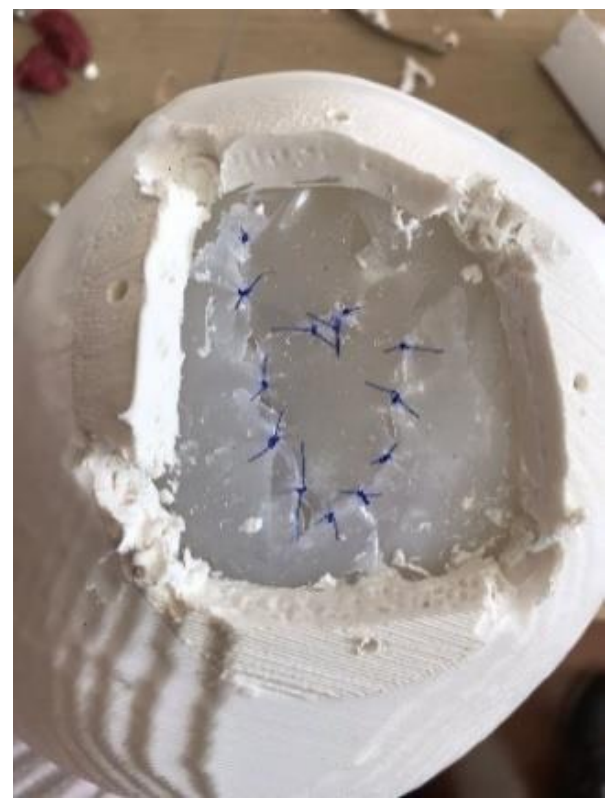

(b)

Figure 10. Tumor inside the brain (a) and suturing the dura mater once the tumor was removed (b).

All the steps of the real surgery were successfully reproduced. During the craniotomy time, the electric drill and specific cutting tools were used (Figure 9a). No difficulties were encountered in this surgical step, and the used material simulated the bone structure very 
well. The removal of the bony flap was followed by the incision of the dura mater, the thin membrane that covers the brain (Figure $9 b$ ).

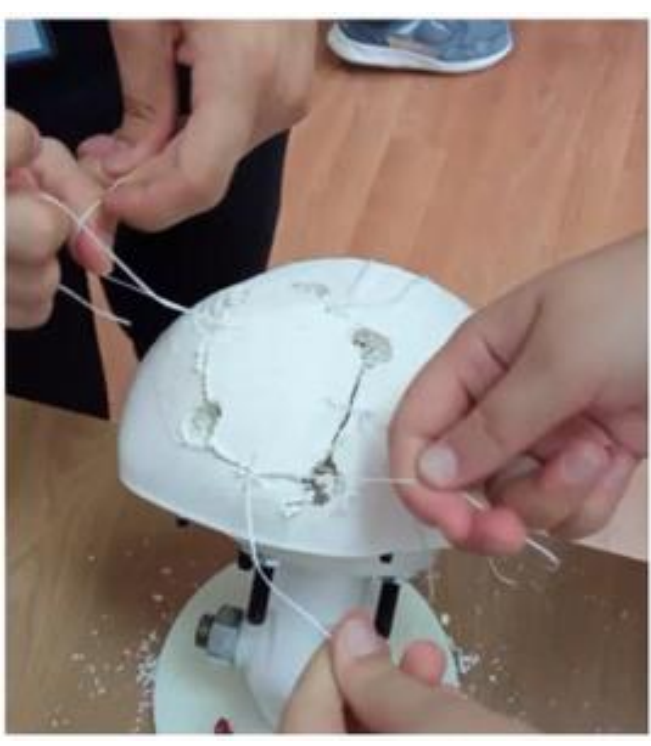

(a)

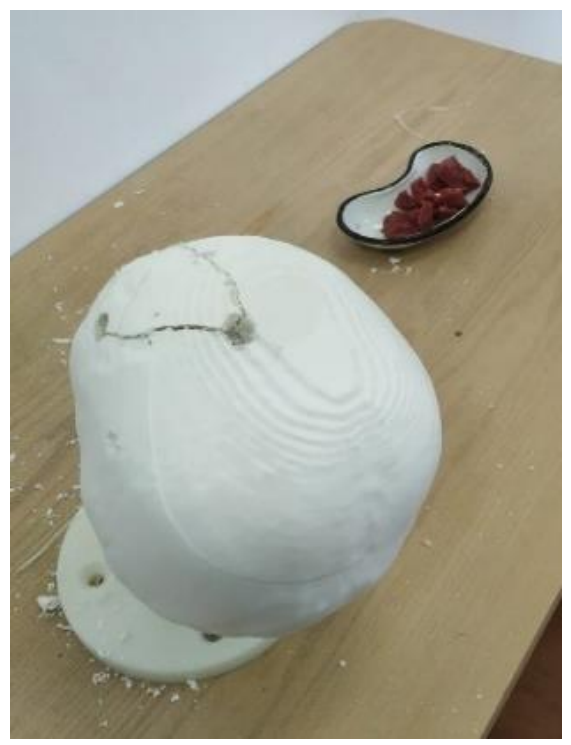

(b)

Figure 11. Final suture of the skull (a) with the tumor removed (b).

The next surgical step was the intracerebral tumor ablation. In this 3D reconstruction, the tumor had a hard consistency, and therefore the ablation was performed piece by piece, using cutting and dissecting tools (Figure 10a).

Total removal of the well-defined tumor formation was performed, and the dura mater was sutured in place using simple interrupted stitches. The material used in this case was very similar to other popular duraplasty materials available on the market (Figure 10b).

After the duraplasty, the bone flap was fixed in place using thick sutures, with very satisfactory results (Figure 11a,b).

The overall process developed by the students in the summer school is recorded in Video S1.

According to the comments of the students and the general observations during the workshop, the experience was very enriching, providing a greater vision of the intervention. They could put in practice their skills in terms of cutting the skull and dura mater, removing the tumor, and sewing both dura mater and skull, with a model quite similar to the real intervention they would face in an operating room.

Additionally, the students were asked to reply a five-question survey about their feelings with the 3D synthetic models they had worked with. These questions were focused on the usefulness of the synthetic models as a method for developing neurosurgical skill, evaluating the feelings obtained with the model approach compared to a reality surgery, in addition to evaluating whether this tool was useful for learning and the potentiality of using this method in different medical specializations. Finally, their level of satisfaction was evaluated. The related results are shown in Figure 12, where it can be concluded that the contribution of these models in neurosurgery is necessary and beneficial to improve the skills of future neurosurgeons.

In this work, we reflected that $90 \%$ of the students considered the 3D models strongly useful to improve their skills in neurosurgery, $40 \%$ thought that this model was enough to feel the sensation of being in a real surgery, $100 \%$ considered this practical activity necessary in different sectors of medicine, $90 \%$ thought that the AM was an effective tool to support training and pre-clinical trial of medicine professionals, and $90 \%$ were very satisfied with the practical activity with these 3D models. 
Q1. Do you think that the 3D models of the workshop have been useful to improve skills in neurosurgery?

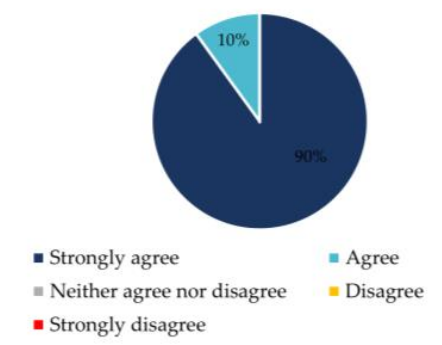

Q3. Do you think that this kind of training material is necessary for the practical activity in the lab for students of medicine, in different medical specializations (traumatology, neurosurgery, etc.)?

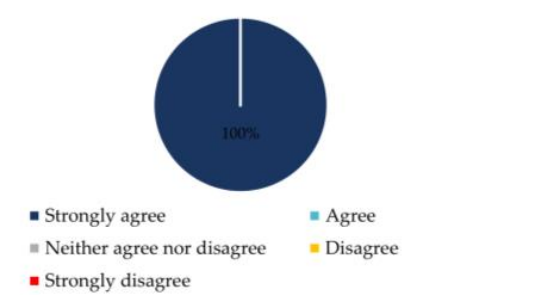

Q2. Were these 3D models realistic enough to feel that you were carrying out a surgery close to reality?

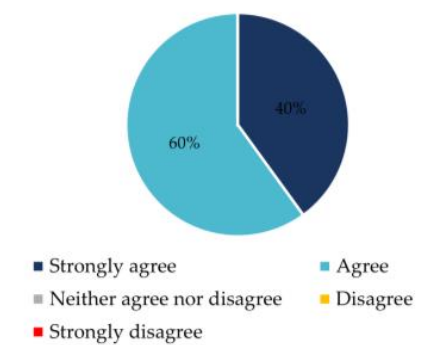

Q4. Do you think that additive manufacturing/3D printing is an effective tool to support training and pre-clinical trial of professionals of medicine?

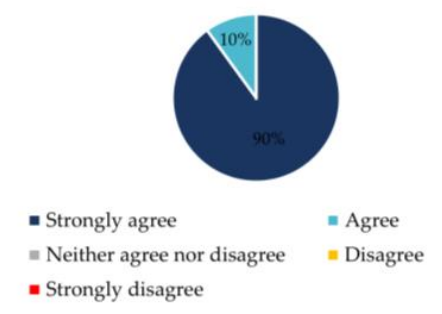

Q5. Show your level of general satisfaction with the practical activity carried out with the $3 \mathrm{D}$ models in the summer school.

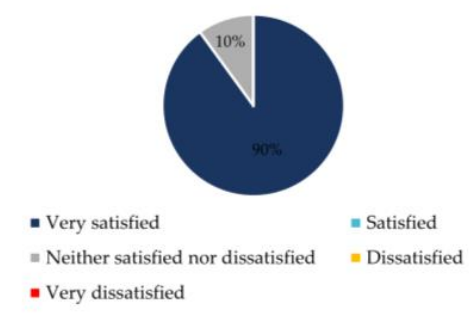

Figure 12. Survey on 3D models.

From the perspective of neurosurgeons, the proposed training approach of real case reconstruction and simulation of surgery brings about important benefits. For resident physicians, it is a very good opportunity to practice basic surgical maneuvers before performing the procedure on the real patient. This greatly shortens the learning curve and at the same time the patient is treated with the utmost respect from an ethical point of view.

Furthermore, for senior neurosurgeons, it is a great way to practice very complicated cases, which often have a very low incidence. That is why the role of surgery simulation is even greater.

After experimenting with these synthetic models, the neurosurgeons in charge of the workshop were also asked for suggestions to improve the synthetic models. Although the overall rating was quite good, the following suggestions and related solutions were provided and detailed:

- Make the dura mater slightly harder. This can be achieved by changing the proportions of the Ecoflex silicone.

- Make the skull a little harder. Although several cutting tests were carried to select the $30 \%$ infill density for the skull in the working area, this value can be slightly increased to make the skull harder for the cutting process.

- Add more pieces of crushed PLA that simulate calcium deposits to the tumor model. This can be easily achieved by crushing and adding more PLA to the tumor mixture. 


\section{Conclusions}

In this work, a set of processes and materials were proposed to manufacture synthetic models for neuro-oncology training, in a very realistic and economical manner. All the models were produced in an economically affordable way since it has been possible to reduce both the manufacturing time and the quantities of mixtures with high cost. Furthermore, the results obtained in the case of students in neurosurgery who practiced with these models have been quite good, even though some aspects could be improved in future model elaborations. Additionally, this procedure may be applicable not only for training sessions, but also for the preparation of clinical cases. The advantages of the use of molds and silicone casting will not be so relevant in such a case, but the production time of one complete model would still be faster following this approach than completely 3D printing the entire models. Apart from this, the synthetic models could be combined with virtual or augmented reality techniques, thus enhancing the training experience.

Supplementary Materials: The following are available online at https://www.mdpi.com/article/10.3 390/app112411823/s1, Video S1: Surgical training.

Author Contributions: Conceptualization, V.S., C.-N.C., M.M. and R.P.; methodology, M.M., R.P. and J.G.; software, Y.R.; validation, M.M. and R.P.; formal analysis, R.P. and Y.R.; investigation, Y.R., C.-N.C., R.P., J.G., M.M., I.C. and V.S.; resources, V.S., M.M. and I.C.; data curation, R.P. and J.G.; writing-original draft preparation, Y.R., R.P., C.-N.C. and I.C.; writing-review and editing, Y.R., I.C. and R.P.; visualization, J.G., R.P., V.S. and C.-N.C.; supervision, V.S., M.M. and I.C.; project administration, C.-N.C., M.M., V.S. and I.C.; funding acquisition, V.S., M.M. and I.C. All authors have read and agreed to the published version of the manuscript.

Funding: This research was funded by the BrainIT project (Brain Revealed: Innovative Technologies in Neurosurgery Study, 2018-1-RO01-KA203-049317) from the Erasmus+ Programme of the European Union.

Institutional Review Board Statement: Not applicable.

Informed Consent Statement: Not applicable.

Data Availability Statement: The data presented in this study are available within the article.

Conflicts of Interest: The authors declare no conflict of interest.

\section{References}

1. Di Piazza, E.; Pandolfi, E.; Cacciotti, I.; Del Fattore, A.; Tozzi, A.E.; Borro, L. Bioprinting technology in skin, heart, pancreas and cartilage tissues: Progress and challenges in clinical practice. Int. J. Environ. Res. Public Health 2021, 18, 10806. [CrossRef] [PubMed]

2. Tiberio, F.; Cacciotti, I.; Frassanito, P.; Nocca, G.; Tamburrini, G.; Arcovito, A.; Lattanzi, W. Personalized Bone Reconstruction and Regeneration in the Treatment of Craniosynostosis. Appl. Sci. 2021, 11, 2649. [CrossRef]

3. Ganguli, A.; Pagan-Diaz, G.J.; Grant, L.; Cvetkovic, C.; Bramlet, M.; Vozenilek, J.; Kesavadas, T.; Bashir, R. 3D printing for preoperative planning and surgical training: A review. Biomed. Microdevices 2018, 20, 65. [CrossRef]

4. Shah, K.J.; Peterson, J.C.; Chamoun, R. 3D Printed Models in Neurosurgical Training. Compr. Healthc. Simul. Neurosurg. 2018, 43, 47-64.

5. Mashiko, T.; Otani, K.; Kawano, R.; Konno, T.; Kaneko, N.; Ito, Y.; Watanabe, E. Development of three-dimensional hollow elastic model for cerebral aneurysm clipping simulation enabling rapid and low cost prototyping. World Neurosurg. 2015, 83, 351-361. [CrossRef] [PubMed]

6. Wurm, G.; Lehner, M.; Tomancok, B.; Kleiser, R.; Nussbaumer, K. Cerebrovascular biomodeling for aneurysm surgery: Simulationbased training by means of rapid prototyping technologies. Surg. Innov. 2011, 18, 294-306. [CrossRef] [PubMed]

7. Kimura, T.; Morita, A.; Nishimura, K.; Aiyama, H.; Itoh, H.; Fukaya, S.; Sora, S.; Ochiai, C. Simulation of and training for cerebral aneurysm clipping with 3-dimensional models. Neurosurgery 2009, 65, 719-725. [CrossRef] [PubMed]

8. Waran, V.; Narayanan, V.; Karuppiah, R.; Owen, S.L.F.; Aziz, T. Utility of multimaterial 3D printers in creating models with pathological entities to enhance the training experience of neurosurgeons: Technical note. J. Neurosurg. 2014, 120, 489-492. [CrossRef]

9. Ryan, J.R.; Almefty, K.K.; Nakaji, P.; Frakes, D.H. Cerebral Aneurysm Clipping Surgery Simulation Using Patient-Specific 3D Printing and Silicone Casting. World Neurosurg. 2016, 88, 175-181. [CrossRef]

10. Nagassa, R.G.; McMenamin, P.G.; Adams, J.W.; Quayle, M.R.; Rosenfeld, J.V. Advanced 3D printed model of middle cerebral artery aneurysms for neurosurgery simulation. 3D Print. Med. 2019, 5, 11. [CrossRef] 
11. Wanibuchi, M.; Noshiro, S.; Sugino, T.; Akiyama, Y.; Mikami, T.; Iihoshi, S.; Miyata, K.; Komatsu, K.; Mikuni, N. Training for Skull Base Surgery with a Colored Temporal Bone Model Created by Three-Dimensional Printing Technology. World Neurosurg. 2016, 91, 66-72. [CrossRef]

12. Kondo, K.; Harada, N.; Masuda, H.; Sugo, N.; Terazono, S.; Okonogi, S.; Sakaeyama, Y.; Fuchinoue, Y.; Ando, S.; Fukushima, D.; et al. A neurosurgical simulation of skull base tumors using a 3D printed rapid prototyping model containing mesh structures. Acta Neurochir. 2016, 158, 1213-1219. [CrossRef]

13. Dho, Y.S.; Lee, D.; Ha, T.; Ji, S.Y.; Kim, K.M.; Kang, H.; Kim, M.S.; Kim, J.W.; Cho, W.S.; Kim, Y.H.; et al. Clinical application of patient-specific 3D printing brain tumor model production system for neurosurgery. Sci. Rep. 2021, 11, 7005. [CrossRef] [PubMed]

14. Naftulin, J.S.; Kimchi, E.Y.; Cash, S.S. Streamlined, inexpensive 3D printing of the brain and skull. PLoS ONE 2015, 10, e0136198 [CrossRef] [PubMed]

15. Waran, V.; Narayanan, V.; Karuppiah, R.; Pancharatnam, D.; Chandran, H.; Raman, R.; Rahman, Z.A.A.; Owen, S.L.F.; Aziz, T.Z. Injecting realism in surgical training-Initial simulation experience with custom 3D models. J. Surg. Educ. 2014, 71, 193-197. [CrossRef]

16. Cráneos Con Traumas Craneoencefálicos Obtenidos Mediante Fabricación Aditiva Para Fines Didácticos en Neurocirugía I accedaCRIS. Available online: https:/ / accedacris.ulpgc.es/handle/10553/58077 (accessed on 18 October 2021).

17. Galford, J.E.; McElhaney, J.H. A viscoelastic study of scalp, brain, and dura. J. Biomech. 1970, 3, 211-221. [CrossRef]

18. Basser, P.J. Interstitial pressure, volume, and flow during infusion into brain tissue. Microvasc. Res. 1992, 44, 143-165. [CrossRef]

19. Miga, M.; Paulsen, K.; Kennedy, F.; Hoopes, J.; Hartov, A.; Roberts, D. Initial In-Vivo Analysis of 3D Heterogeneous Brain Computations for Model-Updated Image-Guided Neurosurgery. Med. Image Comput. Comput. Assist. Interv. 1998, $1496,743$. [PubMed]

20. Miller, K.; Chinzei, K.; Orssengo, G.; Bednarz, P. Mechanical properties of brain tissue in-vivo: Experiment and computer simulation. J. Biomech. 2000, 33, 1369-1376. [CrossRef]

21. Taylor, Z.; Miller, K. Reassessment of brain elasticity for analysis of biomechanisms of hydrocephalus. J. Biomech. 2004, 37, 1263-1269. [CrossRef]

22. Marosi, C.; Hassler, M.; Roessler, K.; Reni, M.; Sant, M.; Mazza, E.; Vecht, C. Meningioma. Crit. Rev. Oncol. Hematol. 2008, 67, 153-171. [CrossRef] [PubMed]

23. Meningioma | Radiology Reference Article I Radiopaedia.org. Available online: https:/ / radiopaedia.org/articles/meningioma? lang=us (accessed on 13 October 2021).

24. Kekere, V.; Alsayouri, K. Anatomy, Head and Neck, Dura Mater. StatPearls 2021. Available online: https://europepmc.org/ article/NBK/nbk545301 (accessed on 18 October 2021). [PubMed] 